\title{
Influence of Gender on Ischemia-Reperfusion Injury in Lungs in an Animal Model
}

\author{
H. MRAZKOVA ${ }^{1}$, R. LISCHKE ${ }^{1}$, J. HERGET ${ }^{2}$ \\ ${ }^{1}$ Third Department of Surgery, University Hospital Motol and First Medical School, Charles \\ University in Prague, Prague, Czech Republic, ${ }^{2}$ Department of Physiology, Second Medical School, \\ Charles University in Prague, Prague, Czech Republic
}

Received December 8, 2015

Accepted April 15, 2016

On-line August 19, 2016

\section{Summary}

As with other organ transplants even lung transplantation raises the question of the possibility of the influence of gender on ischemia-reperfusion injury. This is a current topic especially for increasingly utilized method of lung transplantation from nonheart-beating donors, where reperfusion preceded by a period of warm and cold ischemia with subsequent treatment options for lung graft reperfusion. For measurements we used our laboratory previously created and validated animal model for ex vivo lung transplantation. As with other organ systems of our monitoring resulted protective effect of female sex on ischemia reperfusion lung injury. In two of the three parameters that were monitored, we found a significant difference. In females, higher oxygen transfer ability after reperfusion was manifested as well as lower perfusion pressure (vascular compliance). Conversely, weight gain (the development of pulmonary edema) in males was not significant difference from the females. These conclusions could cause further studies leading to influence the selection of appropriate donor grafts.

\section{Key words}

Lung transplantation/ex vivo • Reperfusion injury/prevention and control • Gender difference • Animal model

\section{Corresponding author}

H. Mrazkova, Third Department of Surgery, University Hospital Motol and First Medical School, Charles University in Prague, V Uvalu 84, 15006 Prague, Czech Republic. Fax: + 420224431 005. E-mail: hana.mrazkova@fnmotol.cz

\section{Introduction}

As in other areas of medicine, in the field of lung transplantation there is the question of the influence of gender on the survival and thriving of the graft. Lung ischemia-reperfusion (IR) injury leading to lung failure is an important clinical problem mainly during transplantation from non-heart-beating donors (NHBDs), allowing the treatment of the lung outside the body. However, the number of patients that could benefit from lung transplantation greatly exceeds the number of donors available (Cypel et al. 2009). Despite refinements in lung preservation and improvements in surgical techniques and perioperative care, ischemia-reperfusion-induced lung injury remains a significant cause of early morbidity and mortality after lung transplantation (De Perrot et al. 2003). Therefore, as in the previous study (Mrazkova et al. 2015), we focused our experiment on the period of IR injury in NHBDs and we studied the sex differences during this period.

The presumption of a different tissue response to IR injury in males and females is based on previous studies in other organ systems (Harada et al. 2001, Müller et al. 2000, Murphy et al. 2007) and on the gender difference in lung diseases based on Carey et al. (2007). It is well known that numerous health problems are affected by gender (Ostadal et al. 2009).

Free radical mediated injury occurring in ischemic tissue after reperfusion is a major cause of damage in lung transplantation. Hypoxia accelerates the production of reactive oxygen species (ROS) such as 
superoxide anion, hydroxyl radical and hydrogen peroxide (De Perrot et al. 2003, Kennedy et al. 1998).

Bae and Zang (2005) and Wang et al. (2006) observed gender differences in cardioprotection in some animal studies suggesting that, compared to males, intact pre-menopausal females (without exogenous estrogen treatment) have reduced IR injury. Barp et al. 2010 indicate that protection against oxidative damage is provided by enzymatic and non-enzymatic antioxidant defenses.

The aim of our study is to confirm or refute the protective influence of the female sex, for ischemiareperfusion injury in lung tissue, as is the case with the protective influence against ischemia-reperfusion injury in other organ systems.

\section{Materials and Methods}

Two groups of adult male Wistar rats and two groups of female Wistar rats were subjected to experiments in accordance with the European Community and NIH guidelines for using experimental animals. Two to three month old male or female Wistar rats weighing $250 \pm 30 \mathrm{~g}$ were divided into four groups with 6 animals per group.

Two experimental groups (M-male, F-female, Table 1) passed the protocol for non-heart-beating-donors (NHBD). The experimental procedure was based on the protocol used in previous studies in our laboratory (Hodyc et al. 2008, Mrazkova et al. 2015) (Fig. 1).

Table 1. Experimental and control groups - schematic protocol.

\begin{tabular}{|c|c|c|c|c|}
\hline \multirow[b]{2}{*}{ Experiment } & \multirow[b]{2}{*}{ Groups } & $\begin{array}{c}\text { Warm ischemia } \\
90 \mathrm{~min}\end{array}$ & $\begin{array}{c}\text { Cold ischemia } \\
60 \mathrm{~min}\end{array}$ & $\begin{array}{l}\text { Reperfusion - } \\
2 \text { h experiment }\end{array}$ \\
\hline & & No ventilation & No ventilation & $\begin{array}{c}\text { Ventilation } \\
21 \% \mathrm{O}_{2}+5 \% \mathrm{CO}_{2} \\
\text { balanced with } \mathrm{N}_{2}\end{array}$ \\
\hline \multirow[t]{2}{*}{ Control groups } & $\mathrm{Cf}$ & & & $\mathrm{X}$ \\
\hline & $\mathrm{Cm}$ & & & $\mathrm{X}$ \\
\hline \multirow[b]{2}{*}{ Experiment groups } & $\mathrm{F}$ & $\mathrm{X}$ & $\mathrm{X}$ & $\mathrm{X}$ \\
\hline & M & $\mathrm{x}$ & $\mathrm{X}$ & $\mathrm{x}$ \\
\hline
\end{tabular}

Cf - control group female rats, $\mathrm{Cm}$ - control group male rats, $\mathrm{F}$ - experimental group female rats, $\mathrm{M}$ - experimental group male rats.

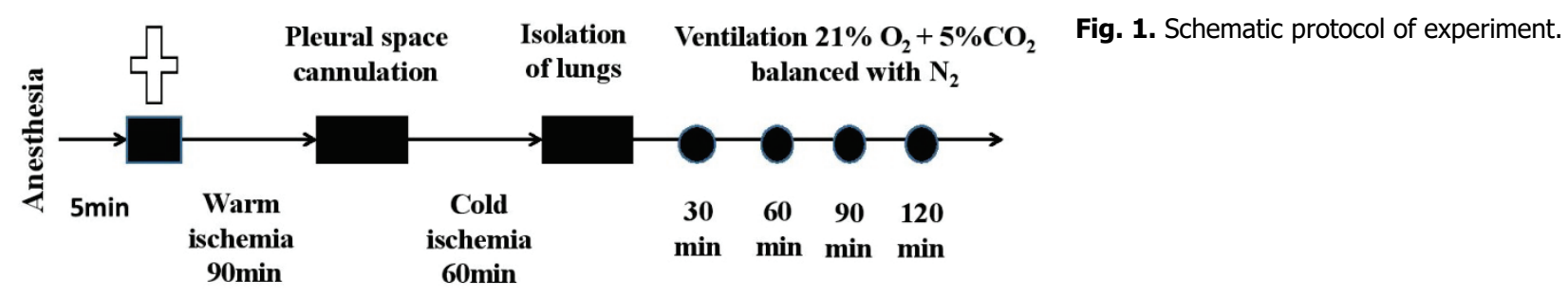

The experimental animals were anesthetized with thiopental $(100 \mathrm{mg} / \mathrm{kg} \mathrm{BW} \mathrm{IP})$, placed in the supine position and secured to the table. $250 \mathrm{IU}$ of heparin was administered into the liver under direct vision. After $5 \mathrm{~min}$, the animals were euthanized by an overdose of sodium thiopental ( $250 \mathrm{mg} / \mathrm{kg}$ BW IP) and we cannulated their trachea. Then followed a period of warm ischemia, when these animals were kept at room temperature without ventilation for $90 \mathrm{~min}$.

After a period of warm ischemia, we opened the thorax and cannulated both pleural cavities - one cannula for inflow and a second one served for the outflow of the perfusion solution (PSS with $5 \%$ of Ficoll) which was at a temperature of $12{ }^{\circ} \mathrm{C}$ and was circulated through the chest of the experimental animal. It was placed in a cooling chamber at a temperature of $12^{\circ} \mathrm{C}$ for $60 \mathrm{~min}$ (cold ischemia). During the period of cold ischemia, the animals were not ventilated.

Then the lungs were isolated and perfused using the standard method described previously (Hodyc et al. 
2008, Mrazkova et al. 2015). The tracheal cannula was connected to the ventilator and the lungs were ventilated by positive pressure (inspiratory pressure $12 \mathrm{~cm} \mathrm{H}_{2} \mathrm{O}$, expiratory pressure $3 \mathrm{~cm} \mathrm{H} \mathrm{H}_{2} \mathrm{O}$ ) with a gas mixture containing $21 \% \mathrm{O}_{2}+5 \% \mathrm{CO}_{2}$ balanced with $\mathrm{N}_{2}$ (Herget and Chovanec 2010). The pulmonary artery and the left atrium were cannulated. Using a peristaltic pump, the lungs were perfused in a constant flow mode $(4 \mathrm{ml}$ per $100 \mathrm{~g}$ body weight per $\min$ ) with a saline solution containing $4 \%$ Ficoll and meclofenamate (6-10 mol/l). The lungs were suspended by the trachea on the force transducer in a heated $\left(38^{\circ} \mathrm{C}\right)$ humidified chamber and allowed to stabilize for $15 \mathrm{~min}$ before the measurement of lung function. The outflow from the left atrial cannula was recirculated into the perfusate reservoir, and the outflow pressure was set to $-2 \mathrm{~mm} \mathrm{Hg}$.

We assessed the pulmonary functions for 120 min after 15-min stabilization from the beginning of the perfusion. The pulmonary perfusion pressure was monitored via a transducer connected to the inflow cannula (PowerLab, ADI Instruments). The lung weight gain was measured continually by a force transducer on which the isolated lungs were suspended. After a $20 \mathrm{~min}$ equilibration period, the first measurement of oxygen transport ability was performed. We took two samples of perfusion solution - an arterial sample from the inflow and a venous sample from the outflow cannula. The partial pressure of oxygen was measured immediately after sampling $\left(\mathrm{ABL}^{\mathrm{TM}} 5\right.$, Radiometer Medical $\mathrm{A} / \mathrm{S}$, Copenhagen, Denmark). Since we used isolated lungs, it was necessary to desaturate the inflow perfusate artificially by bubbling the perfusate in the reservoir with $5 \% \mathrm{CO}_{2}+95 \% \mathrm{~N}_{2}$ for $5 \mathrm{~min}$. Thus, the increase in oxygen partial pressure between the inflow and outflow cannula $\left(\Delta \mathrm{pO}_{2}\right)$ was a measure of the ability of the lung to transport oxygen from the alveoli into the perfusate.

After a 10 -min recovery period, the reactivity to angiotensin II $(0.4 \mu \mathrm{g})$ and to acute hypoxic challenge $\left(0 \% \mathrm{O}_{2}+5 \% \mathrm{CO}_{2}+74 \% \mathrm{~N}_{2}\right)$ was tested in two cycles as a test of lung viability (Herget and Chovanec 2010). One lung of group $\mathrm{M}$ and one of group $\mathrm{F}$ were discarded due to poor response to hypoxic challenge.

In time periods of 30, 60, 90 and $120 \mathrm{~min}$ from the beginning of the perfusion, the lung transport ability for oxygen was measured in the same way as described above and in these time intervals the values of perfusion pressure and lung weight gain were recorded.

Control groups of animals (Cm-controls male, Cf-controls female, Table 1) were anesthetized and the isolation of the lung was performed in the same manner as described above. However, the perfusion of the lungs started immediately after isolation, thus the lungs did not undergo warm and cold ischemia.

Free radical concentration, biological antioxidant potential (PAT test), was measured in perfusate samples taken from the venous reservoir after $90 \mathrm{~min}$ of warm ischemia PAT test (FRAS-II, Italy) (Bertuglia and Giusti 2005). The test measures antioxidant potential by chromatic change of ammonium thiocyanate. The intensity of this will be directly proportional to the plasma ability to reduce the ferric ions to ferrous ion.

\section{Statistical analysis}

For the statistical evaluation we used ANOVA for repeated measures, Fisher's PLSD test and Games/Howell post-hoc test as appropriate. Mean values \pm SEM are presented.

\section{Results}

The experimental and control groups contained the lungs which survived until the end of all functional assessments. All preparations retained significant vasoconstrictor responses to angiotensin II and acute ventilator hypoxia.

\section{Oxygen transport ability}

Measuring oxygen transport ability using the arterial-venous difference in oxygen partial pressure, we found significantly higher oxygenation capability in female rat lungs $(\mathrm{F})$ compared to the male rat lungs $(\mathrm{M})$. The best oxygen transport ability, especially at the beginning of perfusion, was observed in the control female group (Cf), and not only was it significantly higher than the experimental groups (F, M), but also than the control male group (Cm) (Fig. 2).

\section{Pulmonary perfusion pressure}

In constant flow perfusion, the pulmonary arterial pressure is determined by the resistance of pulmonary vasculature to perfusion flow. It was significantly lower in the female experimental lungs (F) than in the male rat group (M) (Fig. 3).

We did not notice a significant difference between the control groups $(\mathrm{Cf}, \mathrm{Cm})$ or between the experimental (F, M) and control groups (Cf, $\mathrm{Cm}$ ). 


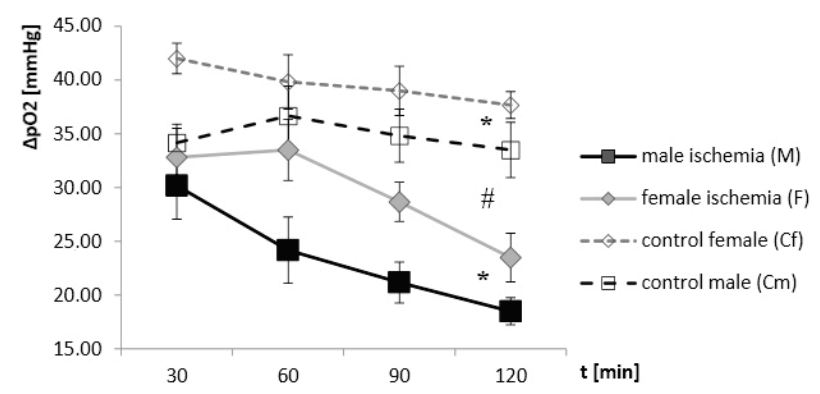

Fig. 2. Oxygen transport ability in control and ischemic lungs of female and male rats. * significant sex difference $(p<0.05)$, \# significant difference between control and experimental groups $(p<0.05)$.

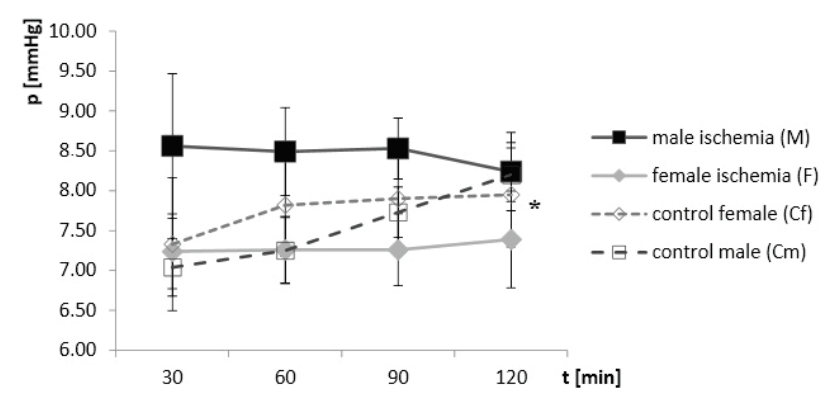

Fig. 3. Pulmonary perfusion pressure in control and ischemic lungs of female and male rats. * significant sex difference $(p<0.05)$.

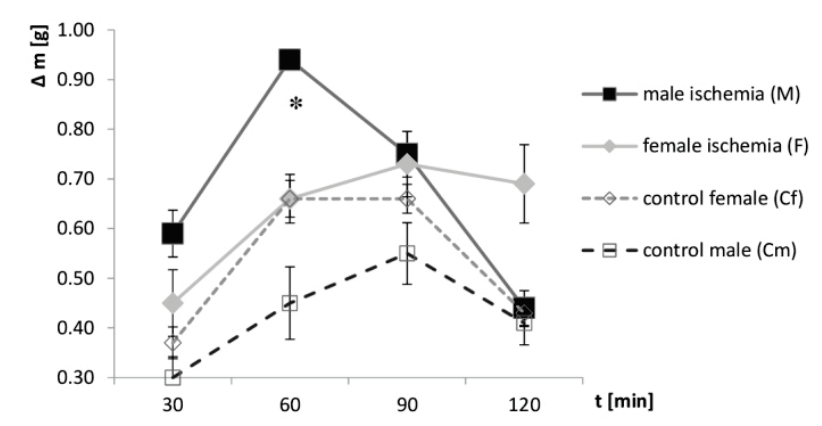

Fig. 4. Lung weight gain in control and ischemic lungs of female and male rats. ${ }^{*}$ significant difference $(p<0.05)$ between the experimental male and control male group.

\section{Weight gain}

Weight gain during the experiment was caused by the development of pulmonary edema. There was no significant difference between experimental male and female groups (F, M). The only significant difference was observed between the experimental male and control male group (M, Cm) $(\mathrm{p}<0.05)$ (Fig. 4).

\section{ROS measurement}

The values of biological antioxidant potential (PAT) indicated higher oxygen radical stress in male rat preparations that went through the period of warm ischemia. PAT test in perfusate of experimental female rats was $350 \pm 30 \mathrm{IU}$ Carr and in experimental male rats $225 \pm 35$ IU Carr.

\section{Discussion}

From our study, which focused on the influence of gender difference on IR injury of lung after cold and warm ischemia in NHBD protocol, we made three conclusions:

1) There is a gender-linked difference in tolerance of warm and cold ischemia based on the significantly lower ability to transport $\mathrm{O}_{2}$ in the lungs of experimental males versus females.

2) The female sex also has a significant protective effect on the development of vascular resistance to perfusion flow after IR injury, which resulted in significantly higher perfusion pressure in experimental male animals.

3) In our observation of weight gain as proof of the development of pulmonary edema, we did not see significant sexual dimorphism in experimental groups.

A main cause of damage occurring in ischemic lung tissue after reperfusion is the release of free radicals (Kennedy et al. 1989, McCord 1985, Hoidal et al. 1998). During reperfusion, the sudden availability of oxygen to act as a cofactor allows xanthine oxidase to convert purine substrate accumulated during ischemia to uric acid, with superoxide anions and hydrogen peroxide $\left(\mathrm{H}_{2} \mathrm{O}_{2}\right)$ forming as byproducts (Kennedy et al. 1989). Hydroxyl radicals are potent oxidants that cause tissue injury by initiating lipid peroxidation of cell membranes and oxidative inactivation of critical cell proteins (Kennedy et al. 1989, Cohen et al. 1985).

Why are the females more resistant to IR lung injury? The increased resistance to ROS has been shown by several studies on laboratory animals (for a review see Carrey et al. 2007). Firstly, estrogens exert antioxidant activity. This has not been fully elucidated and involves multiple mechanisms (Harada et al. 2001). Numerous studies in vitro have shown that estrogens have the potential to affect the redox chemistry of transition metals and, in particular, iron and copper. By this mechanism, estrogens are thought to inhibit peroxidation of membrane lipids and lipoproteins (Lacort et al. 1995, Ruiz-Larrea et al. 1995). The down regulation of inducible NO synthase may be another factor (Kawachi et al. 2000, Yu et al. 2006). The link to the increase in 
pulmonary capillary permeability and to the difference in perfusion pressure is evident. Estrogens inhibit lowdensity lipoprotein oxidation (Zuckerman et al. 1996), decrease lipoprotein concentrations (Mosca et al. 1998) and reduce superoxide anion production (Arnal et al. 1996).

An ex vivo experiment in isolated lung perfused by the solution without blood cells and its own original plasma favors the possibility that mechanisms other than the plasma concentration of sex hormones protect females from increased ROS damage. The gender differences in reactivity in vitro were also shown in systemic arteries. It was explained by the difference in the handling of intracelular $\mathrm{Ca}^{2+}$ (Loukotova et al. 2002).

We did not find a difference in the development of pulmonary edema in the male and female experimental groups. This may indicate that gender difference does not affect pulmonary capillary permeability.

Simultaneously, it is necessary to comment that increased weight gain occurs even in control groups (Cf, Cm) which were not exposed to hot and cold ischemia. The reason why the weight of lungs increased after the initial two hours of the experiment even in the control group cannot be attributed only to the formation of pulmonary edema. Lung weight may also increase due to the increase in intravascular volume as a result of vasodilatation or vascular recruitment. Impairment of oxygen transport may result from local changes in the ventilation/perfusion ratio (Mrazkova et al. 2015).

Our experimental measurement leads to the conclusion that female lungs are generally more resistant to ischemia-reperfusion injury after warm and cold ischemia. Therefore, it is necessary to consider, in terms of graft survival, but also from the overall economic standpoint, whether to prefer female grafts for NHBD ex vivo reperfusion lungs.

\section{Conflict of Interest}

There is no conflict of interest.

\section{Acknowledgements}

Supported by the project (Ministry of Health, Czech Republic) for conceptual development of research organization 00064203 (University Hospital Motol, Prague, Czech Republic) as well as by grants GACR COST LD14068, GACR 13-01710S and IGA NT13358. We thank lab assistants in the laboratory of the Department of Physiology, 2nd Medical School, especially Ms Olga Hniličková for assisting in the experiments.

\section{References}

ARNAL JF, CLAMENS S, PECHET C, NEGRE-SALVAYRE A, ALLERA C, GIROLAMI JP, SALVAYRE R, BAYARD F: Ethinylestradiol does not enhance the expression of nitric oxide synthase in bovine endothelial cells but increases the release of bioactive nitric oxide by inhibiting superoxide anion production. Proc Natl Acad Sci USA 93: 4108-4113, 1996.

BAE S, ZHANG L: Gender differences in cardioprotection against ischemia/reperfusion injury in adult rat hearts: focus on Akt and protein kinase C signaling. J Pharmacol Exp Ther 315: 1125-1135, 2005.

BARP J, ARAÚJO A, FERNANDES T, RIGATTO KV, LLESUY S, BELLO-KLEIN A, SINGAL P: Myocardial antioxidant and oxidative stress changes due to sex hormones. Braz J Med Biol Res 35: 1075-1081, 2002.

BERTUGLIA S, GIUSTI A: Role of nitric oxide in capillary perfusion and oxygen delivery regulation during systemic hypoxia. Am J Physiol Heart Circ Physiol 288: H525-H531, 2005.

CAREY MA, CARD JW, VOLTZ JW, GERMOLEC DR, KORACH KS, ZELDIN DC: The impact of sex and sex hormones on lung physiology and disease: lessons from animal studies. Am J Physiol Lung Cell Mol Physiol 293: L272-L278, 2007.

COHEN G: The Fenton reaction. In: CRC Handbook of Methods for Oxygen Radical Research. GREENWALD RA (ed.), CRC Press, Inc., Boca Raton, FL, 1985, pp 55-64.

CYPEL M, RUBACHA M, YEUNG J, HIRAYMA S, TORBICKI K, MADONIK M, FISCHER S, HWANG D PIERRE A, WADDELL TK, DE PERROT M, LIU M, KESHAVJEE S: Normothermic ex vivo perfusion prevents lung injury compared to extended cold preservation for transplantation. Am J Transplant 9: 2262-2269, 2009.

DE PERROT M, LIU M, WADDELL TK, KESHAVJEE S: Ischemia-reperfusion-induced lung injury. Am J Respir Crit Care Med 167: 490-511, 2003. 
HARADA H, PAVLICK KP, HINES IN, HOFFMAN JM, BHARWANI S, GRAY L, GRISHAM MB: Selected contribution: effects of gender on reduced-size liver ischemia and reperfusion injury. $J$ Appl Physiol 91: 2816-2822, 2001.

HERGET J, CHOVANEC M: Isolated perfused murine lung a well characterized preparation for studying lung vascular function. Drug Discov Today 7: 3-4, 2010.

HODYC D, HNILICKOVA O, HAMPL V, HERGET J: Pre-arrest administration of the cell-permeable free radical scavenger tempol reduces warm ischemic damage of lung function in non-heart-beating donors. $J$ Heart Lung Transplant 27: 890-897, 2008.

HOIDAL JR, XU R, HUECKSTEADT T, SANDERS KA, PFEFFER K, STURROCK AB: Lung injury and oxidoreductases. Environ Health Perspect 106: 1235-1239, 1998.

KAWACHI S, HINES IN, LAROUX FS, HOFFMAN J, BHARWANI S, GRAY L, LEFFER D, GRISHAM MB: Nitric oxide synthase and postischemic liver injury. Biochem Biophys Res Commun 276: 851-854, 2000.

KENNEDY TP, RAO NV, HOPKINS CH, PENNINGTON L, TOLLEY E, HOIDAL JR: Role of reactive oxygen species in reperfusion injury of the rabbit lung. J Clin Invest 83: 1326-1335, 1989.

LACORT M, LEAL AM, LIZA M, MARTIN C, MARTINEZ R, RUIZ-LARREA MB: Protective effect of estrogens and catecholestrogens against peroxidative membrane damage in vitro. Lipids 30: 141-146, 1995.

LOUKOTOVA J, KUNES J, ZICHA J: Gender-dependent difference in cell calcium handling in VSMC isolated from SHR: the effect of angiotensin II. J Hypertens 20: 2213-2219, 2002.

MCCORD JM: Oxygen-derived free radicals in postischemic tissue injury. N Engl J Med 312: 159-163, 1985.

MOSCA L: Estrogen and atherosclerosis. J Investig Med 46: 381-386, 1998.

MRAZKOVA H, LISCHKE R, HODYC D, HERGET J: The protective effect of hypercapnia on ischemia-reperfusion injury in lungs. Respir Physiol Neurobiol 205: 42-46, 2015.

MULlER V, LOSONCZY G, HEEMANN U, VANNAY Á, FEKETE A, REUSZ G, SZABO AJ: Sexual dimorphism in renal ischemia-reperfusion injury in rats: possible role of endothelin. Kidney Int 62: 1364-1371, 2000.

MURPHY E, STEENBERGEN C: Gender-based differences in mechanisms of protection in myocardial ischemiareperfusion injury. Cardiovasc Res 75: 478-486, 2007.

OSTADAL B, NETUKA I, MALY J, BESIK J, OSTADALOVA I: Gender differences in cardiac ischemic injury and protection - experimental aspects. Exp Biol Med 234: 1011-1019, 2009.

RUIZ-LARREA B, LEAL A, MARTIN C, MARTINEZ R, LACORT M: Effects of estrogens on the redox chemistry of iron: a possible mechanism of the antioxidant action of estrogen. Steroids 60: 780-783, 1995.

WANG M, CRISOSTOMO P, WAIRUIKO GM, MELDRUM DR: Estrogen receptor-alpha mediates acute myocardial protection in females. Am J Physiol Heart Circ Physiol 290: H2204-H2209, 2006.

YU Z, KUNCEWICZ T, DUBINSKY WP, KONE BC: Nitric oxide-dependent negative feedback of PARP-1 transactivation of the inducible nitric-oxide synthase gene. J Biol Chem 281: 9101-9109, 2006.

ZUCKERMANN SH, BRYAN N: Inhibition of LDL oxidation and myeloperoxidase dependent tyrosyl radical formation by the selective estrogen receptor modulator raloxifene (LY139481 HCL). Atherosclerosis 126: $65-75,1996$. 